Int. J. Electrochem. Sci., 14 (2019) 7423 - 7436

\title{
Corrosion Behavior of A356/SiC Alloy Matrix Composites in $3.5 \%$ NaCl Solution
}

Ociel Rodríguez Pérez ${ }^{1, *}$, J. A. García-Hinojosa ${ }^{1}$, F. J. Rodríguez Gómez ${ }^{1}$, S. Mejia-Sintillo², V.M. Salinas-Bravo ${ }^{4}$, R. Lopes-Sesenez, J.G. Gonzalez-Rodriguez ${ }^{2}$, Cesar A. Garcia-Pérez ${ }^{3}$.

${ }^{1}$ Departamento de Ingeniería Metalúrgica, Facultad de Química, Universidad Nacional Autónoma de México, Circuito Exterior, Ciudad Universitaria, 04510, Ciudad de México, México.

${ }^{2}$ Centro de Investigación en Ingeniería y Ciencias Aplicadas-IICBA, Universidad Autónoma del Estado de Morelos, Av. Universidad 1001, Col. Chamilpa, 62210, Cuernavaca, Morelos, México. ${ }^{3}$ Tecnológico de Monterrey, Escuela de Ingeniería y Ciencias, Ave. Eugenio Garza Sada 2501, Monterrey, N.L., México, 64849.

${ }^{4}$ Instituto Nacional de Electricidad y Energías Renovables, Departamento de Combustión, Interior Internado Palmira, Cuernavaca, Mor., México.

*E-mail: ggonzalez@uaem.mx

doi: $10.20964 / 2019.08 .33$

Received: 2 April 2019 / Accepted: 21 May 2019 / Published: 30 June 2019

The corrosion behavior of the A356 (0, 5, 10, and 15 wt.\%) SiC composites produced by mechanical alloying (MA) and uniaxially pressing/sintering route was studied through electrochemical and surface analysis techniques in $3.5 \mathrm{wt} . \% \mathrm{NaCl}$. The corrosion behavior of the samples was investigated by using electrochemical techniques. The corrosion resistance for the unreinforced A356 aluminum alloy was higher than the composites, however, when the A356 aluminum alloy was reinforced with SiC particles, composites were susceptible to a localized type of corrosion at the matrix/SiC particles interface. This made that although the passive zone for composites was wider with a pitting potential value slightly higher than those for base alloy, passivation current density was higher.

Keywords: A356/SiC composites, mechanical alloying, electrochemical techniques.

\section{FULL TEXT}

(C) 2019 The Authors. Published by ESG (www.electrochemsci.org). This article is an open access article distributed under the terms and conditions of the Creative Commons Attribution license (http://creativecommons.org/licenses/by/4.0/). 